INTERNATIONAL DESIGN CONFERENCE - DESIGN 2018

https://doi.org/10.21278/idc.2018.0503

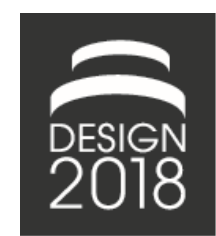

\title{
FAIL EARLY, FAIL OFTEN: EXPLORING STANFORD'S ME310 COURSE AS A BASIS TO IMPROVE INNOVATION OUTPOST EFFICACY
}

\author{
D. Stenholm, D. Moore, L. Leifer and D. Bergsjö
}

\begin{abstract}
In this case study, we compare knowledge transfer between innovation teams in two contexts: an industry-sponsored graduate student capstone course to their corporate sponsors, and innovation outposts (IOs) to their parent companies. Through interviews with different stakeholders, we identified best practices for and challenges to innovation transfer, with personal relationships and tangible communication of ideas through prototypes being key to success. We call for more longitudinal studies to explore both the soft and hard benefits of innovation outposts.
\end{abstract}

Keywords: knowledge management, knowledge transfer, innovation, innovation outpost, design education

\section{Introduction}

As the "Father of Silicon Valley", Fred Terman nurtured the university-industry relationships that has led to many of the technological innovations we know today (Tajnai, 1985). Silicon Valley leads the world in venture capital investment, hosts a high concentration of technical talent, leads the United States in patent filings, and is home to numerous research institutions and research and development (R\&D) labs (Melville et al., 2017).

To tap into the Silicon Valley ecosystem, companies such as SAP, Nestlé, Toyota, Daimler, and BMW have established innovation outposts (IO): small offices geographically separated from company headquarters designed to tap into new technologies, cutting-edge research, and skilled labor that could be useful to their parent company. For example, BMW's Palo Alto Technology Office looks out for new trends, find highly specialized and unique technical knowledge and technologies, and establish contacts with potential external partners.

Following the Silicon Valley mantra of "fail early, fail often", IOs seek to explore many ideas and technologies simultaneously, discarding those that seem less promising. The meaning of this mantra is not to create shoddy products, but rather to quickly yet rigorously test an idea before investing too much on development of something that would prove to be a failure later on.

A higher number of knowledge transfer channels between IO and HQ as well as high learning capacity permits the HQ as a unit in organizational network to successfully apply and replicate knowledge. In the other direction, it also increases the IOs innovative capability by shared learning, knowledge transfer, and information exchange (Tsai, 2001). However, bringing this innovation home to parent companies can be difficult, and not much research has been done on the efficacy of these IOs. It remains to be seen if there is a significant return on investment to their parent companies (Di Fiore, 2017).

To address this knowledge gap, we compare the innovation transfer between IOs and their parent companies to a well-established industry-sponsored design course at Stanford University. The students 
in this course have similar relationships with their corporate sponsors as IOs do with their parent companies. From this comparison, we have identified challenges to quantifying impact of IOs, and highlight a number of perceived best practices that could be further built on.

\section{Background}

Volatile markets and new product introductions force organizations to innovate to survive (Cavusgil et al., 2003), and today's shortened product life cycles compound the difficulty of staying in front of technology trends. Various scholars have looked at measuring the organizational structure and relationships that ensure effective innovation capability (Cavusgil et al., 2003). In theory, IOs should improve companies' abilities to produce new ideas and products by improving access to new technologies, research, and talent.

\subsection{Innovation's importance to long-term company success}

Rothaermel (2015) defines innovation as "the commercialization of an invention". At various points in product or business lifecycles, companies will have different goals regarding the outcome of any innovation process.

Incremental development is the steady improvement of a product or system (Pisano, 2015) as opposed to radical innovation, related to changing the behaviour of the market by novel methods, materials or technologies, often creating a new category of products. Market breakthrough innovation is when there is a high impact on the market while using existing technology. Technology breakthrough innovation is more focused on the technology itself but when the impact on the market is lower (Rothaermel, 2015). Disruptive innovation is also commonly discussed, which is when an innovation have a big impact on the surrounding system regarding the product or service and it doesn't necessary include large innovation in market or technology but can be accomplished by combining them in new setting. In between these stages we argue that there exists adjacent innovation focusing on adapting existing technology that the company do not use/deploy and/or targeting existing market that the company do not currently serve Booz, Allen \& Hamilton (1982) (Figure 1).

To maintain competitiveness, organizations must balance exploitation of core business strategy with exploration of new possibilities. Focusing on existing products leads to short-term success but risks missing where the market is going. It is easy for companies to routinely maintain market position through retroactive-looking design and development. On the other hand, only focusing on future products can bring higher short-term risk and a potential to miss future technology shifts entirely.

Large, established companies often do incremental development internally, but regularly seek external input for breakthrough innovation.

One of the most central benefits of using an external (to R\&D) innovation team is to gather the widely distributed knowledge that exists in the world. This can more easily take advantage of open innovation, or a process that makes more effective use of internal and external knowledge to increase value inside the organization (Chesbrough, 2012). However according to Chesbrough (2012) there is still much to learn about its problems, boundary conditions, and critical success factors.

\subsection{Ambidexterity in innovation strategy}

Early research on the tension between exploration and exploitation within the same organization suggested potential incompatibility (Burns and Stalker, 1961; March, 1991). However in 1996, Tushman and O'Reilly (1996) launched the concept of organizational ambidexterity, "the ability of organizations to perform well in both exploration and exploitation".

More recently, Raisch and Birkinshaw (2008) claim that the most common approach to organizational ambidexterity has been to establish structurally separate units for exploration and exploitation.

IOs are quintessential examples of this ambidextrous model, with innovation teams having large responsibility for the exploration side of organizational ambidexterity. Few IOs even take part in exploitation of ideas or technologies once identified or developed. With this approach, companies can still pursue traditional exploitation of existing markets while simultaneously exploring avenues for future development. 


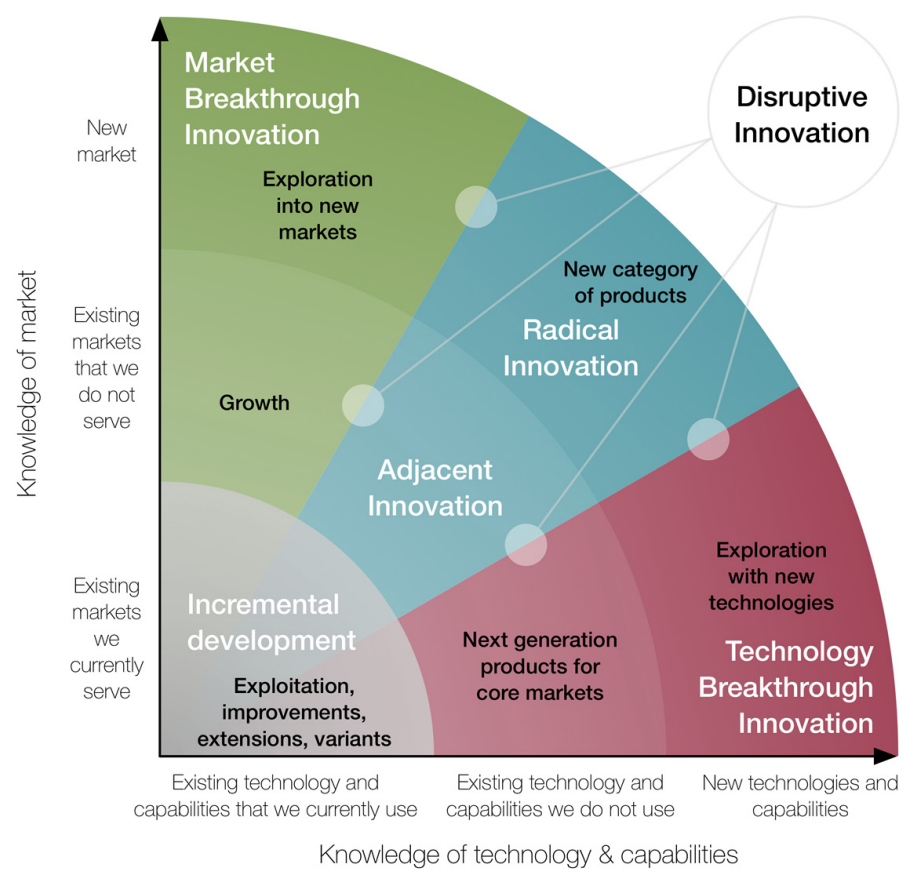

Figure 1. This map organizes common terminologies used regarding innovation. Companies may have different goals with any innovation process, from incremental development to radical or breakthrough innovation. Organizational ambidexterity literature suggests companies should balance between exploration (the lower left corner) and exploitation outside of the lower left corner) in order to stay competitive in future markets (adapted from Booz, Allen \& Hamilton, 1982)

However, knowledge transfer between exploration and exploitation arms of a company is critical for success. Internal knowledge transfer and diffusion within $R \& D$ have been recognized as a major management challenge for international companies.

\subsection{Perceived value of IOs in innovation strategy}

\subsubsection{Tap into innovation ecosystem}

Bosch-Sijtsema and Bosch (2014) discuss the innovation ecosystem as based on external cooperation and defined as a collaborative arrangement through which firms combine their individual offerings into a coherent customer-facing solution. However, literature in this field often focuses on the external strategy, but neglects aligning it with the internal R\&D strategy. Bosch-Sijtsema and Bosch (2014) argue that there are dependencies and connections between the different innovation levels. The innovations resulting from the innovation ecosystem become requirements for $\mathrm{R} \& \mathrm{D}$, that in due time need to be manufactured, sold, and supported for customers. Successful companies manage to align their different strategies, exploit the innovation and create a flow of knowledge to their benefit.

\subsubsection{Capitalize on knowledge through university-industry partnerships}

IOs acquire knowledge by networking with universities, startups, and other organizations (Wiklund et al., 2009). Wilson (2012, p. 2) argued that "Universities are an integral part of the skills and innovation supply chain to business... and can only be secured through close collaboration, partnership and understanding between business and universities". Furthermore, he argued that "never before has there been a greater need for a talented, enterprising workforce, for constant innovation in product and service development, for a thriving culture of entrepreneurship, for dynamic leading-edge scientific and technological development and for world-class research that attracts investment." 
Organizations collaborate with universities to gain access to specific knowledge outputs and enable access to a range of resources. Business assistance, extensions services, and accelerator programs transfer university expertise to new technologies and business practices to improve product performance and process efficiency that enhance industrial competitiveness. Organizations who are aware of the benefits of engagement with universities are able to integrate compatible academic capabilities with product development requirements (Philbin, 2012).

Larger organizations might also seek collaboration for other reasons, for example increasing credibility by collaborating with a well-known university or recruiting qualified employees. Through engagement with universities, organizations can access the latest research in their fields and innovative employees in the form of graduates or students on work placements. They are also able to gain access to innovative ideas and opportunities via the networks developed from their university engagement.

\subsubsection{Value proposition of Silicon Valley}

Silicon Valley has a very high concentration of engineering and technical talent, and there is also a highly interconnected group of venture capitalists seeking to invest in early stage companies. As such, there is a preponderance of new ideas combined with talent and resources to execute them. Companies are an integral part of this ecosystem, sponsoring research at universities, and investing in early-stage startups themselves. These are a few of the reasons companies choose Silicon Valley to build IOs.

\section{Stanford's capstone design innovation course, ME310, as a case study for innovation transfer}

Stanford University's capstone design innovation course, $M E 310$, is a microcosm of the Silicon Valley ecosystem. To elucidate the comparison between the course and IOs, we outline the ME310 course structure, identify existing knowledge transfer protocols, and describe their fundamental similarities and differences.

\subsection{Course structure}

ME310 can be summarized as "Global-Team Based Design Innovation with Corporate Partners". High performance engineering design teams create innovative solutions to ambiguous design problems through a process that is facilitated through rich social interaction and physical on-the-spot-experiments (Naveiro and de Souza Pereira, 2008). Every year, 30 to 40 students (mostly from Mechanical Engineering) are organized into small teams to work for three academic quarters on real-world design problems posed by industry sponsors. All students are at the Master's or Ph.D. level and about half of them have previous industry experience. Student teams at Stanford also collaborate with student teams at partner universities around the world, leading to a final unified prototype at the end of the year (Carleton and Leifer, 2009).

Before the academic year, the ME310 teaching team works with corporate sponsors to design a problem statement that addresses specific questions of interest to the sponsor. Key to this prompt is defining the problem's time frame, e.g. 3-5 years in the future, and whatever assumptions or limitations must be made about the design space within that time. The teaching team also works with sponsors to make sure that prompt is very open-ended and does not dictate a solution.

Different from other engineering courses, ME310 does not ask students to build a specific prototype that a corporate sponsor wants to have built. Rather, students simultaneously explore both potential problems and solutions within a larger open-ended space, and in doing so prototype concepts based on the areas of greatest need within that space. In the first academic quarter, students focus on benchmarking the design space and understanding users' needs through needfinding (Patnaik and Becker, 1999). From the end of the first academic quarter and through the end of the third academic quarter students build and test prototypes to explore various elements of the problem and solution spaces, while returning to needfinding and benchmarking as well as needed. The result of the projects can be a representation of a breakthrough market, radical, or technology innovation. The teams often apply or recombine existing technologies in new ways, not pursue fundamental research, and also focus on communicating the potential experience of a future technology to their sponsors. 
Also adopting the "fail early, fail often" mantra, students create numerous prototypes to test the most challenging elements of a design as early as possible. Ideas are quickly discarded if deemed unsuitable for the project, either technologically or through user testing. Both successes and failures are passed onto the corporate sponsor.

\subsection{Value proposition of ME310 to corporate sponsors}

The Stanford teaching team proposes many dimensions of value to companies in exchange for the $\$ 150,000$ (USD) sponsorship: exploration of a design are of the company's choosing, functional proof of concept prototypes, exposure to the design thinking process, access to Stanford professors for research and consulting, networking with representatives from other corporate sponsors, and exposure to graduate students-many of whom work for their sponsors after graduating. Liaisons at parent companies can also get project management experience by managing the student teams. Essentially for the price of one full time engineer in Silicon Valley (also a tax-deductible donation in the US), sponsors get a team of 6-8 students working on the exploration of a design space.

\subsection{ME310 deliverables to corporate sponsors}

ME310 contains four built-in mechanisms that transfer knowledge from the student teams to their corporate sponsors: (1) prototypes, (2) quarterly reports, (3) quarterly presentations with an end of year exhibition, and (4) informal communications such as emails and meetings.

\subsubsection{Prototypes tangibly communicate and demonstrate ideas}

Prototypes range from low-fidelity cardboard mockups to high fidelity, professionally machined models. Generally, students explore the design space with rough prototypes, and communicate with corporate sponsors through more refined prototypes. The resolution of the prototypes is important, as "less expert audiences cannot normally be expected to understand... approximate representations" (Houde and Hill, 1997, p. 373).

\subsubsection{Quarterly reports outline design process, successes, and failures}

Teams write comprehensive documents (often more than 100 pages) at the end of each quarter detailing their design process, findings, and technical development. From these documents, future student teams and corporate liaisons can replicate most elements of the team's work.

Sometimes these documents are even more valuable than the prototype, as they articulate the usercentered design process, not just the end result. This process may be new to the sponsor, and can indicate directions that did not seem promising, saving the corporate sponsor time in their overall innovation strategy.

\subsubsection{Quarterly presentations and end of year exhibition demonstrate vision}

Three presentations, one in the end of each academic quarter, highlight the students' design process, rationale of each critical design move, and need-based motivation for each major prototype. The first two emphasize the team's design successes and failures. The final presentation pitches the teams' products. Teams motivate why they chose to solve a particular problem within the design space. An exhibition known as EXPE follows the final presentations, where teams setup interactive booths to demonstrate their final prototypes.

\subsubsection{Informal communication fills in the rest}

ME310 assigns a "Chief Communication Officer" who is responsible for sending regular updates via email to the liaison. This level of interaction between student teams and their corporate sponsors is highly variable across project sponsors and student teams.

Usually, students and liaisons from the corporate sponsor will meet to discuss the project trajectory. Some meet on a weekly or biweekly basis, while others only meet a few times in the year. An exhibition known as trade show known as EXPE follows the final presentations, where teams setup interactive booths to demonstrate their functioning final prototypes. 


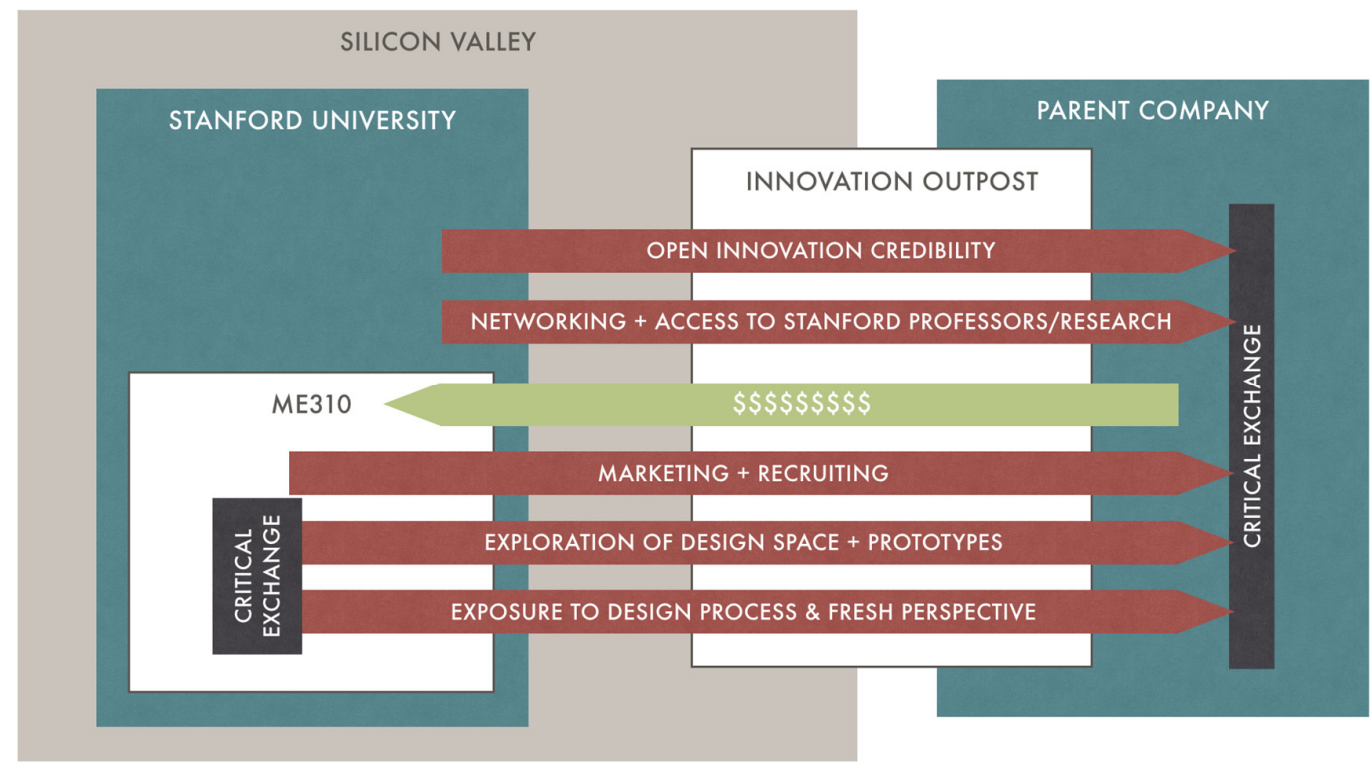

Figure 2. IOs serve as a bridge between the larger Silicon Valley ecosystem (including Stanford and ME310) and a parent company. Values of this relationship (in red) include networking, exploration of design spaces, and exposure to new labor and perspectives. In this paper, we focus on the efficacy of the critical exchanges between ME310 teams and corporate sponsors, innovation outposts to parent companies (in black)

\section{Research frame and method}

On paper, ME310 and IOs both offer the same value to corporate sponsors and parent companies, respectively. Large companies use innovation outposts as a bridge between their headquarters and the Silicon Valley ecosystem, and IOs use ME310 as a direct bridge into Stanford, increasing access to ideas, research, and talent. Both increase open innovation credibility, and the financial investment helps to maintain the Silicon Valley ecosystem by encouraging the development of new ideas and technology. In Figure 2, we highlight the primary returns on investment from ME310 to IOs, and IOs to their parent companies, and in subsequent sections we explore the parallels between these critical exchanges of knowledge.

\subsection{Research questions}

In this case study, we compare the efficacy of knowledge transfer from (1) ME310 teams to their corporate sponsors, and (2) IOs to their parent companies. While the ultimate value of these transfers is unknown and difficult to measure, there is much to learn from the many parallels in these critical transfers of knowledge. We focus on two primary research questions:

1. What are the benefits and challenges of innovation transfer from (1) ME310 to corporate sponsors and (2) innovation outposts (IOs) to parent companies?

2. What lessons can we learn from the comparison to improve innovation transfer?

\subsection{Qualitative data collected through interviews with IOs and ME310 participants}

We interviewed representatives from IOs about their innovation strategy, most often some variant of innovation manager/strategist, product manager and venture capitalist. Some were also corporate sponsors of ME310, and we asked about their experience with the student teams. We also interviewed members of the Stanford ME310 teaching team.

14 Interviews were conducted from January to June 2017. Each interview lasted around 45-60 minutes. As the authors listened to the interviews, key moments were transcribed and clustered on a virtual board of post-it notes to identify common themes, similarities, and differences. 
We also had many semi-structured interviews and conversations with student teams, team coaches, course administrators, and liaisons. A survey including two questions where given to both students and liaisons during the final exhibition, however too few liaisons responded to consider the results valid. However, students from all eight teams responded $(\mathrm{N}=20)$.

We also include case examples from the 2 nd and 3rd authors' experiences as a former student and current professor for ME310, respectively.

\section{Interview themes}

From our interviews, we describe elements of knowledge transfer that interviewees reported did or did not work when working with their corporate sponsor or parent companies.

\subsection{Perceived challenges of effective transfer}

\subsubsection{Clear expectations and tangible deliverables}

ME310's structured deliverables and expectations ensure that knowledge has a good chance to be transferred to their corporate sponsor, as the liaisons have clear ideas of what to expect. ME310 students have a set timeline, assignments, and presentations that mark many points throughout the design process, which keep the project moving forward to the final presentation.

On the other hand, we did not hear about IOs having similar strict timeframes. Some IOs may set internal company presentations or external events such as the Consumer Electronics Show, but in general, these are not as rigid as the academic setting.

For both IOs and ME310, proof of concept prototypes are important vehicles of knowledge transfer. Student teams deliver their final prototypes to liaisons, and instruct them on their usage. IOs report similar success through presentation of proof-of-concept prototypes that demonstrate an idea more clearly than anything on paper, especially to a manager on the other side of the world.

\subsubsection{Open-mindedness}

While there are clear deliverables in ME310, the design process does not always go where the corporate sponsor intended in the problem statement. To this end, liaisons must be open-minded about the project's outcome. One member of the ME310 teaching team expressed that the corporate sponsors are sometimes "a little pushy in one direction especially in the earlier phases of the project, but sometimes that is because that is the way they have been doing it before. But as in a more classic development you need to show them [what they didn't know they needed]". Liaisons who see the project sponsorship as a donation rather than a core part of their innovation strategy are more likely to be satisfied at the end of a project.

Here it is important to emphasize one fundamental difference between ME310 and IOs. While the corporate sponsor and liaisons contribute guidance, context, and real-world experience, the students have ultimate autonomy to go in the direction they choose. For example, a BMW-sponsored project in 2005 tasked students to improve the open-air convertible car experience. Students first tested how a hole in the windshield affected cabin wind dynamics on a small scale car model, then unbeknownst to the liaisons, drilled a hole in the windshield of their full-size test vehicle. A stream of air in between the passenger and driver seats significantly reduced wind buffeting in the cabin, and ended up being a highly novel solution to the identified problem. However, liaisons would not have given this prior approval, and their open-mindedness to the project's outcome was critical in bringing this innovation home to the parent company.

\subsubsection{Inposts}

Several IOs discussed characteristics of successful inposts in their parent organizations: liaisons close to $R \& D$ who adapt and potentially scale innovations. Either formal or informal relationships, inposts help the IO to sell an innovation, further aligning it with the business strategy.

Innovation success depends on knowing and interfacing frequently with liaisons in their parent companies in order to take their ideas further in the organization. 
One interviewee described their IO's communication strategy saying, "We assign each person at our location to some specific area to acquire deep knowledge in, mainly that person contacts the key partner inside HQ... key to success is to know the key partner in $H Q$ to speed up the process". Another interviewee also stressed that "having a good relationship with the business unit on a daily/weekly basis is a necessity".

For decades, the liaisons at ME310 teams' corporate sponsors have been inposts responsible for adopting student projects into the company, and in recent years the ME310 teaching team has sought three liaisons for each student team so the corporate sponsor connection is more robust. This is because one year a team's only corporate liaison retired and the team's final prototype never left its box. Similarly, a longstanding corporate sponsor did not renew the project recently because one of the liaisons left the company and did not adequately transfer ownership of the project to their co-workers. However, there is "no recipe for [guaranteed] success" as one IO manager phrased it.

\subsubsection{Hiring and rotation programs}

Some of the best benefits companies get out of ME310 is the knowledge acquired when they hire student teams.

The potential for a job after the project can be a motivator for students to increase their performance. However, one student also mentioned that this motivation colored design decisions to be more in line with the corporate sponsors' wishes than their own findings and desires.

Analogously, interviewees reported value in employees from their parent companies around the world rotating into the IO for a few months at a time. After spending a few months absorbing the Silicon Valley mindset and entrenched in new technology, employees can bring a fresh perspective to their parent company.

\subsection{Perceived challenges of ineffective transfer}

\subsubsection{Overly specific expectations}

In an open innovation process, parent organizations with narrow-minded expectations of their IO's output, such as direct application of a particular technology, may be disappointed. This is common, as project proposals within organizations are typically well-defined. However open innovation processes do not have a set path or defined goal as they are focused on absorbing all sorts of knowledge from a wide variety of sources. This is a challenge for IOs, as if they diverge too much from their parent company's overall strategy, they risk being closed down. Several interviewees mentioned the need to align innovation strategy with business strategy and to have people who understand and execute the parent company's strategy and innovation areas. This highlights the importance of finding strategic problems that the IO's parent company wants the IO to solve that are also open-ended enough to allow for open innovation to prosper.

One of the interviewees was a venture capitalist with a $\mathrm{PhD}$ in Computer Science, and has looked at applying startup methods within large organizations to spur innovation. He argues that to find disruptive innovation, sharing your failures and lessons learned is the best thing a corporation can offer so the innovation team knows what to avoid, not what to do. This information is not necessarily found in corporate reports, nor is very popular among upper management.

While parent companies are eager to share best practices and desired outcomes, innovation teams should not have limits on their design space. Instead, parent companies should give innovation teams an idea of what has not worked in the past.

\subsubsection{Technology, rather than need-driven innovation}

Many IOs invest in startups and sponsor research for the development of novel technology that can further the company's overall innovation strategy. Companies often need defensible intellectual property (IP) such as patents to ensure that future products are competitive, especially in the technology industry. Hence, patent quotas and technology partnerships are key to IOs' strategy.

However, this motivation can make employees seek novel technology that is not necessarily commercializable or applicable to the company to meet annual targets. Company executives may also 
be fuelled by hip technology highlighted in the media that may or may not be applicable to the company's vision.

While IOs often approach innovation through technology, we believe that ME310's need-driven focus offers an alternative and possibly more productive approach. ME310's design thinking process emphasizes finding and satisfying unmet user needs over defensible IP. By making teams identify real problems first, rather than building technology with no viable application, the incentives of the innovation process are properly aligned with the outcome. Technology and need-driven innovation share the same end goal, however technology driven innovation can lead to technology being produced for technology's sake, which does not help a company's innovation strategy in the end.

Table 1. Summary conclusions and proposed recommendations

\begin{tabular}{|c|c|c|}
\hline $\begin{array}{l}\text { Project } \\
\text { Phase }\end{array}$ & Recommendation & Remember \\
\hline Idea & $\begin{array}{l}\text { * Continuously understand the needs or pain } \\
\text { points from R\&D in order to align the IO projects } \\
\text { to strategic problems. }\end{array}$ & $\begin{array}{l}* \text { Be aware of where in the innovation map (Figure 1) } \\
\text { your project will be. If the project is on the outer front } \\
\text { it might not be possible to align it to existing needs. }\end{array}$ \\
\hline $\begin{array}{l}\text { Make/ } \\
\text { Innovate }\end{array}$ & $\begin{array}{l}\text { * Continuously update the people who are } \\
\text { supposed to adapt the outcome in the end with all } \\
\text { the findings along the process at least weekly or } \\
\text { biweekly. } \\
\text { * Fail early, fail often. Frequently set up what the } \\
\text { next knowledge gap is and prototype to find the } \\
\text { answer. } \\
\text { * Find the right KPI for the process, elaborate on } \\
\text { KPIs such as experiment velocity and learning } \\
\text { velocity. }\end{array}$ & $\begin{array}{l}\text { * Early on in the project, identify methods for } \\
\text { communication that work for both the innovation team } \\
\text { and the receiving parent company liaison. Think about } \\
\text { how frequent the interaction should be and what } \\
\text { information should be communicated. } \\
\text { * Be open and communicate expectations of the } \\
\text { project. } \\
\text { * Be fair to the project, kill it if it does not show } \\
\text { potential to succeed and don't keep it alive because of } \\
\text { reasons such as necessary burn-down rate or reasons } \\
\text { from corporate politics. } \\
\text { * It is not always about the product, it is also about the } \\
\text { innovation process. Seek to critically evaluate and } \\
\text { improve the innovation process. }\end{array}$ \\
\hline $\begin{array}{l}\text { Adapt/ } \\
\text { Scale }\end{array}$ & $\begin{array}{l}\text { * Create an inpost that supports the adaptation } \\
\text { inside the company. The inpost will help the } \\
\text { innovation team to promote the innovation inside } \\
\text { the organization by finding the right people, } \\
\text { finding the right time, quantifying the risk, being } \\
\text { credible, and showing the innovation's costs and } \\
\text { benefits } \\
\text { * Make sure that the innovation team can be } \\
\text { supportive even after concept handover. }\end{array}$ & $\begin{array}{l}\text { * A rotation program might support the adaptation of } \\
\text { both the innovation as well as the culture. Hiring } \\
\text { people if the innovation team members are outside the } \\
\text { company is also a possibility, and likely will benefit IO } \\
\text { and parent company. }\end{array}$ \\
\hline
\end{tabular}

\subsubsection{Generic knowledge without applications}

One resounding theme from the interviews is that companies have trouble absorbing the knowledge produced by IOs. Companies sponsor IOs not because they want knowledge per se, but rather that they want to spur development of products to increase revenue or enter a new market. From a company's financial perspective, the knowledge itself is a critical contributor to, but also a by-product of, the innovation process.

This highlights the critical nature of managing expectations and communicating applicability of ideas through tangible prototypes. If parent companies expect their IOs to product market-ready product concepts, that is a fundamentally different process than open innovation. On the other hand, open innovation will not be successful if the knowledge gleaned is not applicable to some element of the company's overall innovation strategy.

Fundamentally, the goal of both ME310 and IOs is to transfer knowledge by conveying the value of new designs and experiences, not to necessarily create new production-ready products. Few ME310 projects become products on the market, and IOs report similar distancing from production-ready prototypes. The goal of tangible prototypes is to envision an experience a few years in the future that can help to guide R\&D and fundamental research. 


\section{Discussion}

We found many parallels between IOs and Stanford's capstone design innovation course, ME310. These interviews also highlighted challenges in innovation transfer that still exist both for ME310 and IOs alike. Even so, the history and institutional knowledge of ME310 suggests potential ways for IOs to improve the transfer of knowledge back to their parent companies.

As the ME310 process bounces between benchmarking, needfinding, and building, so should IOs work to quickly iterate through technology development. It may be helpful to bounce between technology development, innovation strategy, and business strategy to constantly update priorities based on the best available information. With so many promising technologies, not all may bear fruit for the company simultaneously, and it's impossible to develop them all.

\subsection{Motivation and empowerment}

Both IOs and ME310 teams share the desire to solve problems for a parent organization. ME310 teams and IOs are closely aligned in their goals and desires to solve problems for a parent organization. IOs face a greater impedance mismatch with their parent companies due to the nature of the ambidextrous organizations-they are responsible for exploration while companies overall are more interested in exploitation.

ME310 teams arguably satisfy Daniel Pink's mantra of effective motivation: autonomy, mastery, and purpose (Pink, 2011). Students have freedom to make design and project decisions, have the financial ability to access equipment and learn any necessary skills to complete their project, and seek to solve real problems that address unmet user needs. Based on the fact that ME310's open-ended design prompts often lead to unexpected and creative outcomes, it is likely that IOs would be more productive with free reign over the design space than they do today.

To this end, innovation that truly addresses user needs will be more motivating for innovation teams than technology development for the sake of technology development. The user needs can come from both the parent company's strategic goals and needs identified by the IO, but innovation without purpose can feel shallow to employees.

\subsection{Communication}

Of course, it is important to align innovation strategy and business strategy to make sure the general problems being solved by the IO are within the scope of the company. ME310 accomplishes this through open-ended problem statements that loosely define a problem space, rather than a solutions space. In addition, the frequent updates between the student team and liaisons ensure that any major course corrections are done as early as possible.

Companies could create inposts directly responsible for interfacing with IOs. Ideally, the relationship would be not just professional but also personal to ensure fluid, natural communication. These individuals can help find the right time and place to promote any idea within the parent company. At the same time, this inpost can be responsible for frequent updating of the IO with the company's status and goals.

ME310 has seen some success with the inpost model, particularly with having multiple corporate liaisons interfacing between student teams and their IOs. However it's important to recognize that ME310 teams do not have the same impedance mismatch as their corporate sponsors as both are on the side of exploration.

\subsection{Measuring impact through deliverables}

Fundamentally, it is unrealistic to expect companies' innovation outposts to return a financial profit on the scale of years while a more appropriate timeframe would be decades. One interviewee said that their company initially required output every six months, but radical innovations are not possible in so short a time frame, so they lengthened the timeframe.

A lack of objective measures or perfect knowledge of the future makes it difficult to declare certain technologies as useful to the company's future. Technology may not have tangible impact for decades in an organization or market. Consider the LASER, which took decades to be commercially viable, but 
is now in countless products across the market. However, the lack of immediate quantification is not an excuse to work without a clear structure and regularly fine tuning the process, even if this process is highly different from general R\&D.

As in ME310, we believe IOs should outline specific deliverables for their parent organizations within an agreed-upon, but flexible, timeframe. Depending on the context, time-pressure might be either productive or counter-productive. It could very much hinder innovation by not allowing enough time to penetrate a difficult design space. Ideas are cheap, so innovation teams must be pushed to communicate an idea's value (or lack thereof) through clear prototypes.

A key element missing from current knowledge transfer is discussion of failure. In ME310, while corporate sponsors want to communicate best practices and what they think should be the future direction, the more valuable step for student teams is discussion of what didn't work, and why. Interviews of IO managers also suggest that guidance on how to avoid pitfalls is more valuable than explicit direction. It's very likely that innovative exploration is mainly supported by failures and lessons learned, while incremental exploitation is supported by continuously improving best practices.

\subsection{Limitations and future work}

This is just an exploratory qualitative case study that does not claim statistical significance or broad implications. All survey and interview responses were self-reported, and individuals' memories are subject to the vagaries of time. The student survey sample is not statistically significant, nor does it accurately represent the entire population of ME310 even if all groups are represented---only a subset of one year's students. We also did not capture the experiences of all IOs in Silicon Valley, and recognize that IOs exist all around the world. We hope to expand the dataset in the future, and invite anyone with relevant experience to contact us to be included in future analyses.

The recommendations we make are conjectures based on reported best practices and examples from IOs and ME310. We would hope that future work can quantify, financially or otherwise, the efficacy of these practices. Given the long time constant of innovation, we cannot claim with certainty that these methods work. Longitudinal work should be done to isolate both the soft (i.e. benefit to culture, employee satisfaction) and hard (i.e. net financial gain) value.

While no comparison will be perfect, other comparisons may prove illuminating. For example, public policy labs can serve as IOs for governments, where the output is policy strategy rather than technology.

\section{Conclusion}

With innovation outposts, companies seek to tap into the Silicon Valley ecosystem of talent, research, companies, and universities. Access to new knowledge and talent helps companies to address the limitations of in-house breakthrough innovation as a direct implementation of ambidexterity.

However, organizational ambidexterity has been, and still is, a struggle for many organizations. In the hunt for dividing focus between exploitation and exploration, in this paper we emphasize that knowledge transfer is a critical element of this organizational structure, and both sides can work to improve the success of innovation outposts.

We explored an industry sponsored design course at Stanford University, ME310, as a potential model for effective innovation transfer between IOs and their parent companies. We proposed that ME310's user-centered exploration of a solution space guided by corporate liaisons offers an alternative model for parent companies to manage their IOs and maximize their return on investment. Based on interviews with innovation managers and participants in ME310, we highlighted several potential best practices to improve knowledge transfer between: clear expectations with tangible deliverables, open-mindedness, inposts/personal relationships, and rotation programs. We also highlighted several challenges to knowledge transfer: overly-specific expectations, technology-driven innovation, and the generation of generic knowledge without useful application.

This study scratches the surface of the many factors that hinder the effective knowledge transfer between IOs and their parent companies. While quantifying successful knowledge transfer is difficult, it is clear that this process requires constant collaboration and investment not only in the innovation teams, but also in the receiving end of the parent company. It is never easy to adopt a new technology or mindset, 
and we hope that future work continues to explore how to improve the effectiveness of innovation transfer.

\section{Acknowledgment}

The authors thank all participating companies and faculty and students from ME310 for their support. This research was made possible by grants from Sweden-America Foundation, which are gratefully acknowledged.

\section{References}

Booz, Allen \& Hamilton (1982), New products management for the 1980s, Booz, Allen \& Hamilton Inc.

Bosch-Sijtsema, P.M. and Bosch, J. (2014), “Aligning innovation ecosystem strategies with internal R\&D”, Proceedings of the ICMIT 2014, Singapore, IEEE, pp. 424-430. https://doi.org/10.1109/ICMIT.2014.6942464

Burns, T.E. and Stalker, G.M. (1961), The management of innovation, Oxford University Press.

Carleton, T. and Leifer, L. (2009), "Stanford's ME310 course as an evolution of engineering design", Proceedings of the 19th CIRP Design Conference-Competitive Design, Cranfield University Press, pp. 547-554.

Cavusgil, S.T., Calantone, R.J. and Zhao, Y. (2003), "Tacit knowledge transfer and firm innovation capability", Journal of business \& industrial marketing, Vol. 18 No. 1, pp. 6-21. https://doi.org/10.1108/08858620310458615

Chesbrough, H. (2012), “Open innovation: Where we've been and where we're going”, Research-Technology Management, Vol. 55 No. 4, pp. 20-27. https://doi.org/10.5437/08956308X5504085

Di Fiore, A. (2017), How Corporate HQ Can Get More from Innovation Outposts. [online] Harvard Business Review. Available at: https://hbr.org/2017/05/how-corporate-hq-can-get-more-from-innovation-outposts

Houde, S. and Hill, C. (1997), "What do prototypes prototype", In: Helander, M.G., Landauer, T.K. and Prabhu P.V. (Eds.), Handbook of human-computer interaction, North Holland, Amsterdam, pp. 367-381. https://doi.org/10.1016/B978-044481862-1.50082-0

March, J.G. (1991), "Exploration and exploitation in organizational learning”, Organization Science, Vol. 2 No. 1, pp. 71-87. https://doi.org/10.1287/orsc.2.1.71

Melville, J., Kaiser, J. and Brown, E. (2017), Silicon Valley Competitiveness and Innovation Project. [online] Available at: http://svcip.com/files/SVCIP_2017.pdf (accessed 12.11.2017).

Naveiro, R.M. and de Souza Pereira, R.C. (2008), "Design education in Brazil", Design Studies, Vol. 29 No. 3 , pp. 304-312. https://doi.org/10.1016/j.destud.2008.02.002

Patnaik, D. and Becker, R. (1999), "Needfinding: the why and how of uncovering people's needs", Design Management Review, Vol. 10 No. 2, pp. 37-43. https://doi.org/10.1111/j.1948-7169.1999.tb00250.x

Philbin, S.P. (2012), "Resource-based view of university-industry research collaboration", Proceedings of PICMET '12 / Technology Management for Emerging Technologies, Vancouver, Canada, IEEE, pp. 400-411.

Pink, D.H. (2011), Drive: The surprising truth about what motivates us, Riverhead Books, New York.

Pisano, G.P. (2015), "You need an innovation strategy", Harvard business review, Vol. 93 No. 6, pp. 44-54.

Raisch, S. and Birkinshaw, J. (2008), "Organizational ambidexterity: Antecedents, outcomes, and moderators", Journal of Management, Vol. 34 No. 3, pp. 375-409. https://doi.org/10.1177/0149206308316058

Rothaermel, F.T. (2015), Strategic management, McGraw-Hill, New York, NY.

Tajnai, C.E. (1985), "Fred Terman, the Father of Silicon Valley", IEEE Design \& Test of Computers, Vol. 2 No. 2, pp. 75-81. https://doi.org/10.1109/MDT.1985.294869

Tsai, W. (2001), "Knowledge transfer in intraorganizational networks: Effects of network position and absorptive capacity on business unit innovation and performance", Academy of management Journal, Vol. 44 No. 5, pp. 996-1004. https://doi.org/10.2307/3069443

Tushman, M.L. and O'Reilly III, C.A. (1996), “Ambidextrous organizations: Managing evolutionary and revolutionary change", California Management Review, Vol. 38 No. 4, pp. 8-29. https://doi.org/10.2307/41165852

Wiklund, J., Patzelt, H. and Shepherd, D.A. (2009), "Building an integrative model of small business growth", Small Business Economics, Vol. 32 No. 4, pp. 351-374. https://doi.org/10.1007/s11187-007-9084-8

Wilson, T. (2012), A review of business-university collaboration. [online] Gov.uk. Available at: www.gov.uk/government/uploads/system/uploads/attachment_data/file/32383/12-610-wilson-reviewbusiness-university-collaboration.pdf (accessed 12.11.2017).

Daniel Stenholm, Ph.D. student

Chalmers University of Technology, Industrial and Materials Science

Bäckvägen 18C, 43535 Gothenburg, Sweden

Email: daniel.stenholm@chalmers.se 